\title{
MELNIKOV HOUSE A BIOCLIMATIC ANALYSIS
}

\author{
Jose David Martínez Otalora \\ U. santo Tomas | Colombia | josemartinezo@usantotomas.edu.co \\ Marina Bolshakova \\ South Ural State University | Russia | marishka-cool@mail.ru \\ Anyela Piedad Rojas Celis \\ South Ural State University | Colombia | anyerojas@uan.edu.co \\ Fabián Humberto Almonacid Lara \\ Instituto caro y cuervo | Colombia | fhalmonacid@gmail.com
}

\begin{abstract}
The aim of this article is to recognize the methods of environmental control used by the master of the "constructivist" movement Konstantin Melnikov in a Melnikov's house, a creation whose architectural value has been highlighted on several occasions, it also seeks to demonstrate through modern climate software simulation and analysis tools that in the early 20th century Melnikov consciously used environmental control methods, which makes the afore-mentioned construction a historical example of bioclimatic architecture meant for Russian climate. In order to assess this topic a digital model has been built and different energy simulations were carried out using software such as Climate Consultant, Design Builder and ArchiCAD.
\end{abstract}

Keywords: Melnikov house; Energy efficiency; Temperature comfort; B. Giovani's strategy.

\section{INTRODUCTION}

Konstantin Melnikov (1890-1974) is one of the most influential architects of Russian constructivism due to his innovative ideas about building, indoor space and aesthetics, which were evidenced in works such as his famous Melnikov's house built in 1928,

Melnikov devoted much of his work to the search for comfortable and economic housing that would respond to the climatic and cultural demands of Russian families.

In this article the Melnikov's House will be analyzed from the bioclimatic point of view. Characteristics such as Energy efficiency and the use of environmental control techniques will be simulated using the Climate Consultant, Design Builder and ArchiCAD software.

\section{SITUATION, CLIMATE AND PROGRAM (GENERAL DATA OF THE HOUSE)}

The Melnikov's House was built between 1927-1929. The construction was carried out together with the Moscow Public Services Organization of Construction which declared it as an experimental model of housing which would allow it to have a plot in the center of Moscow for its construction.

The house was located in the residential neighborhood called Arbat (Kuznetsov, 2017). This was an open field on the $n^{0} 10$ of Krivoarbatsky Lane (55 ${ }^{\circ} 44^{\prime} 52.9^{\prime \prime N ~} 37^{\circ}$ $35 ' 22.0 "$ E) which has a humid continental climate with rigorous and long winters and mild and brief summer. There the winter begins at the end of October and ends at the beginning of April with the possibility of descending to -40 degrees Celsius, in summer the temperature ranges between 10 and 30 degrees Celsius and coincides with the maximum amount of the rainfall. The prevailing winds come from the north in summer and from the south west in winter.

The architectural brief fitted to the life of Malnikov, his wife and two children of school age. The house is composed of three floors distributed in two cylinders with equal diameters juxtaposed with each other but with different heights. It has a basement that is intended for heating facilities along with a grocery store. The first floor has a central access to the south, positioned in the lower cylinder. A hall connected to a central corridor distributes to a dining room, a living room, a kitchen, a bathroom, a work room for women, two study rooms for children, a large dressing room and a bathroom. The second level contains a living room and a large common bedroom for the family. The third level is a workshop of double height and a terrace (Khan-Magomedov, 2007).

\section{METHOD FOR SIMULATION}

In order to highlight the strategies proposed by Melnikov, a great number of characteristics of the house were simulated in a virtual environment (Schneider, 2012) with the help of the following steps: 1-Three-dimensional modeling of the house by representing the shape, surfaces and dimensions of the original house taking into account both the surrounding area and buildings. 2Designation of the location: By assigning the model a territory with latitude and longitude within the planet Earth. 3-Introduction of climate databases: By using information collected and organized by climatology institutions for more than 10 years which allow simulations of climate on a modeling. 4-Assignment of materials: By determining the constructive characteristics of the building in terms of materials and their thermal transmittance values $\mathrm{U} 2$ for opaque surfaces and translucent surfaces. 5-Assignment of activities: By determining the use of each space and the 


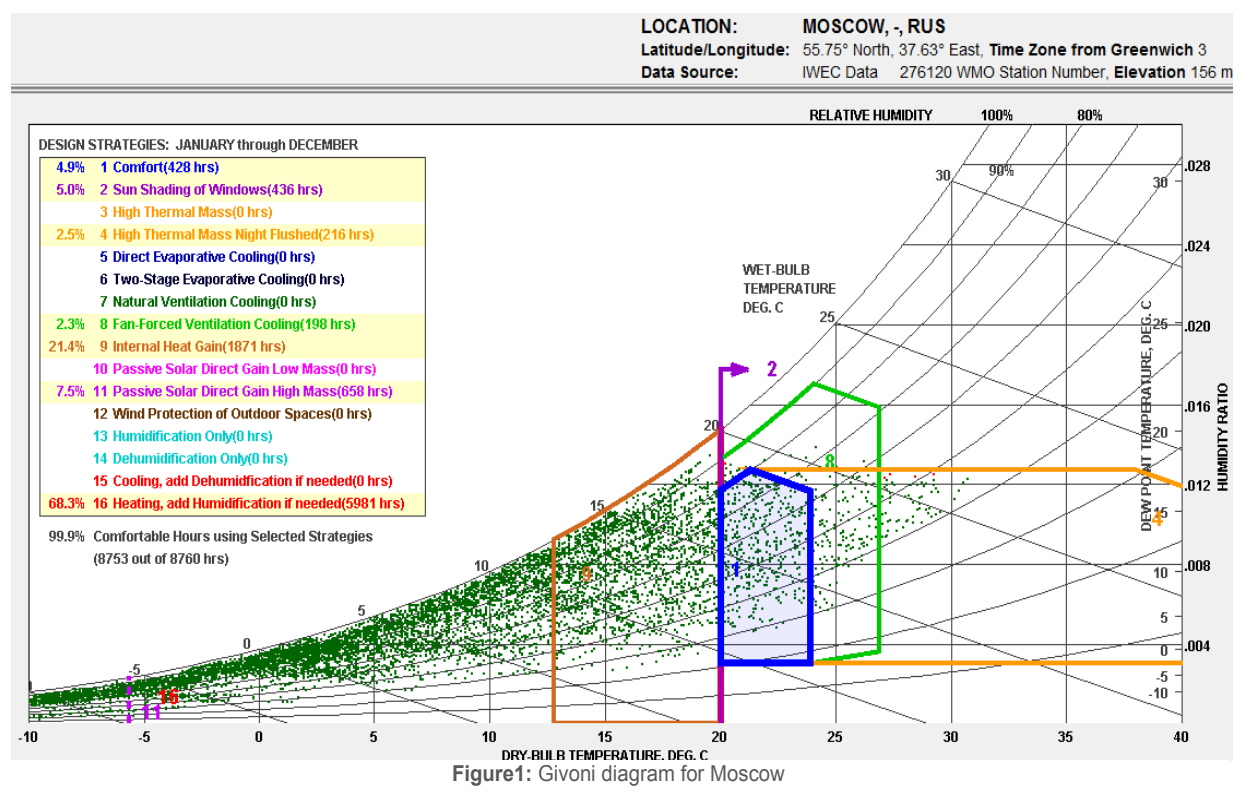

occupancy rate. 6- Heating systems: By introducing the data of the heating and cooling systems or the use of natural ventilation. 7- Simulation: After entering the information to the three-dimensional model the simulations of the variables that need to be analyzed are performed in order to obtain predictions and corresponding graphs. Most energy simulators require the above-mentioned steps for their correct execution.

\section{BIOCLIMATIC STRATEGIES OF CLIMATE CONSULTANT FOR MOSCOW}

The Climate Consultant software and the Energy plus database were used with the purpose of understanding the climatic characteristics of Moscow. In addition to this, the psychometric diagram of Givoni (Givoni, 1982) was used to summarize the obtained data showing the characteristics of air, humidity and temperature in order to assess the thermal sensation and comfort.

The diagram for the city of Moscow (Figure 1) shows the recommendations of Climate Consultant to achieve comfort during all hours of the year as follows: Passive climate control strategies: $4.9 \%$ is equivalent to 428 hours of the year the climate is comfortable, $5 \%$ is equivalent to 436 hours of the year requiring windows with solar protection, $2.5 \%$ is equivalent to 218 hours of the year, a high thermal mass is required to keep energy during the day and that the energy discharges at night, $21.4 \%$ is equivalent to 1871 hours of the year this is required to use internal gains to heat up, $7.5 \%$ is equivalent to 658 hours during the year, is required direct solar gains by high thermal mass. Active air conditioning strategies: $2.3 \%$ is equivalent to 198 hours of the year requires forced cooling ventilation, $68.3 \%$ is equivalent to 5981 hours of the year, heating and humidifier is required if necessary. From this information it can be deduced that in $30 \%$ of the time comfort can achieved with passive strategies, which implies a saving in the use of mechanical air conditioning systems during the year.

\section{BIOCLIMATIC STRATEGIES IN THE MELNIKOV HOUSE}

\section{LOCATION IN THE PROPERTY}

Location determines the connection between the house and its immediate surroundings. The precise balance of sunlight, air circulation and interior temperature all greatly depend on the correct position of the construction and its contact with the outside environment; the correct positioning is the first step to make a house more comfortable and one of the main tactics for energy saving; a correct house orientation will boost lighting and solar radiation and finally avoid excessive energy and heating costs (DeKay \& Brown, 2014).

In this way, it is relevant to observe the solar behavior of the house. Six conditions are simulated to achieve this goal (Figure 2): 1. The accumulated solar radiation during a year; 2 . The solar plot of the house; 3 . The range of shadows of the mentioned buildings; $4-5$. The solar trajectories during winter and summer solstices. 6. The section where the incidence of solar rays is observed during the mid-day solstices

It is also important to highlight the section where the incidence of solar rays is observed during the solstices at noon. According to the above listed information it is evident that the location of the dwelling is determined by two conditions. The first one is the highest annual solar incidence and the second one is the smallest shadow area on the house. 

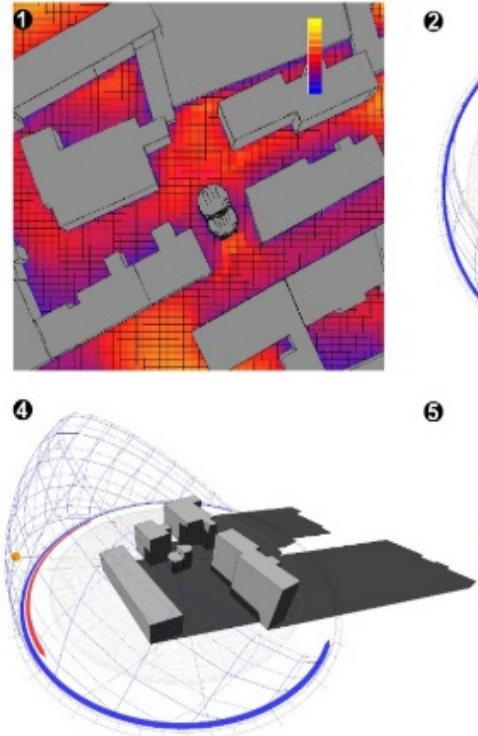

6

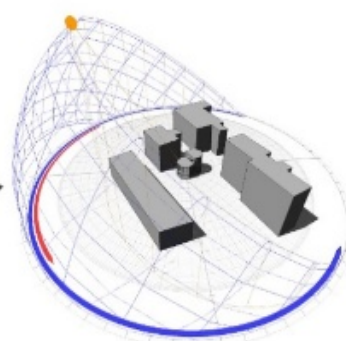

3

(2)

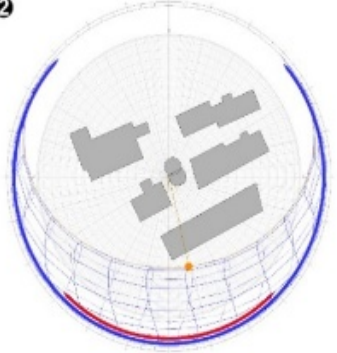

6
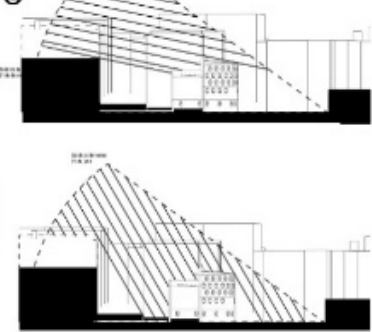

Figure 2: Shadow diagrams and solar studies

1 shows the solar radiation accumulated during all days of the year; there, it is observed that the south side of the property where the main façade is located is one of the places with the highest solar incidence in the year. The highest solar incidence is related to the shading ranges in the winter and summer solstices. In the figures 3,4 and 5 this connection determines the area of the south façade as the area with the lowest shade of the site and with the highest annual solar incidence.

Besides, along the year the house receives more sunlight in the morning compared with sunlight received by sunset, given that the building on its west side is lower than the one on the east side allowing sun rays coming through from 6 am during the summer solstice and from 9:30 am during the winter solstice. However, one of the elements affecting the building is the increased height of the building on the south side; at its planning stage, its adjoining south was 3 floors high which made possible direct sunlight exposition throughout the year, an adjacent building exceeding 6 floors has decreased the number of months with sun to 9 resulting in increased energy consumption in winter though.

\section{2-SOLAR CAPTATION}

Due to its lack of any ecological impact, as well as to its self-sufficient and perennial high quality, solar energy is the main source of energy in the climate control for bioclimatic buildings. In this way, one of the recent objectives for bioclimatic housing is to save and increase solar exposure; consequently the passive solar capture technique was developed, which allows to benefit from the sun energy without the usage of mechanical or electrical systems, this technique seeks comfort by setting up the architectural elements and sun exposure in order to achieve a natural conditioning. (Sayigh, 2019).
In order to observe the house performance using the strategies of a solar capture it is necessary to simulate during the year the percentage of shaded area on the windows by the south façade, also the direct solar radiation on the glazed surfaces of the south facade and finally the direct solar gains of the house (Figure 3).

\section{GLAZING}

From the first graph it can be concluded that the nonshaded area in the south façade is $80 \%$ larger during most of the year and in most of the hours, having its lowest percentage close to the summer solstice, this is caused, both for the absence of eaves in the house design or roof elements that generate shade in the glazed wall of the south. In the graph 2 it is evident that the south glazed façade boasts an integrated annual direct radiation of $12330 \mathrm{KWH}$, consuming the sun light that radiates on the materials and the air increasing their temperature and transferring the excess of energy as infrared radiation; this type of radiation is trapped in space and cannot escape from the glass façade accumulating and producing a greenhouse effect that captures and conserves the heat, increasing the temperature inside the house.

\section{THERMAL MASSES.}

The considerable thickness of the red brick shell shaping the Melnikov's House makes up a thermal mass with a good heat capacity which absorbs energy when the environment temperature is higher than the one of the mass, usually during the daylight hours, and returns the thermal energy when the environment is colder, what normally happens at night; this process is repeated every day without reaching thermal equilibrium. This strategy of combined indirect capture over a large glazed surface achieves a solar gain of $25740 \mathrm{KWH}$ helping to maintain the temperature within the comfort range inside, avoiding excessive use of heating (Holyoke \& Heschong, 1980). 


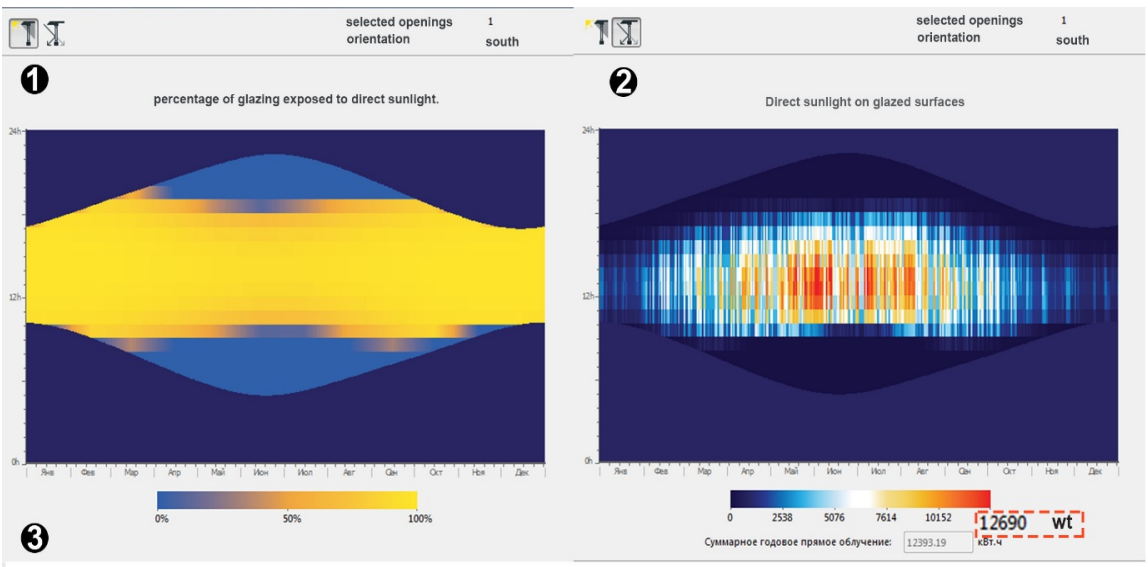

\section{Energy balance of the project}
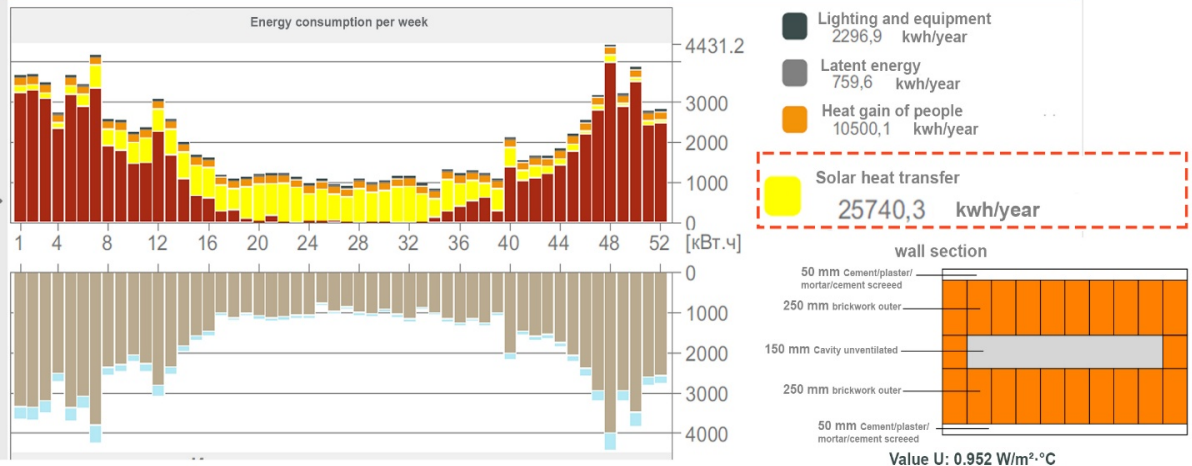

Figure 3: solar captation

\section{3-DISTRIBUTION OF ACTIVITIES AND THEIR EFFECTS ON TEMPERATURE}

One of the main purposes of architectural space distribution in any building is to provide the best conditions for the development of our daily activities according to our work cycles and the activities carried out inside, allowing for the number of people per square meter, occupancy time and their lighting and energy consumption requirements. On this way, when people carry out activities producing heat, this resulting temperature is an internal gain and must be taken into account on the search for comfort. (Figure 4)

Other decisive comfort-wise aspect is the connection between volume and height of the inhabited spaces. Under indoor ideal conditions cold air is located above the floor while hot air stays near to the ceiling although both air masses are separated by a horizontal barrier creating a temperature difference between the upper part of the space and the ground; in low height spaces, the closest the horizontal barrier to the height of people in such space, the lower the energy required to produce a sense of comfort [9]. Consequently, the connection between area, volume and number of people is relevant for the optimal development of activities in a particular space.

The graphics below display the distribution for the main spaces of the Melnikov's House which is determined by the number of square meters, the height of the space, its location, the type of activity, the number of people inside, the time the space is occupied and the metabolic load produced (Dunichkin, Poddaeva \& Golokhvast, 2019).

\section{FIRST FLOOR:}

The access hall is located on the first floor of the south cylinder and it is $5 \mathrm{~m}^{2}$ with a height of $2.6 \mathrm{~m}$; it receives the sun light directly and it is the area of the house with the largest connection to the outside, there a lock stopping cold air passing to this area when the door is opened and therefore it becomes a thermal dimmer for the outside temperature.

The dining room is located on the first floor of the south cylinder, it is $11 \mathrm{~m}^{2}$ with a height of $2.6 \mathrm{~m}$ and a volume of $28.6 \mathrm{~m}^{3}$; it is directly affected by the sun's rays from which it obtains a thermal gain. This is a first-floor area with a higher solar incidence since one of its windows lets direct radiation in from the south. It is normally occupied three times a day which matches to the feeding hours. It is usually occupied by 4 people in a sedentary state who produce a sensitive average metabolic load of $69.6 \mathrm{w} / \mathrm{m}^{2}$ and a latent load of $63.8 \mathrm{w} / \mathrm{m}^{2}$ each for a total of $278 \mathrm{w} / \mathrm{m}^{2}$ sensible load and $255 \mathrm{w} / \mathrm{m}^{2}$ of latent load.

The kitchen is located on the first floor's south cylinder. It is $7 \mathrm{~m}^{2}$ with a height of $2.6 \mathrm{~m}$ and a volume of $18.2 \mathrm{~m}^{3}$. 

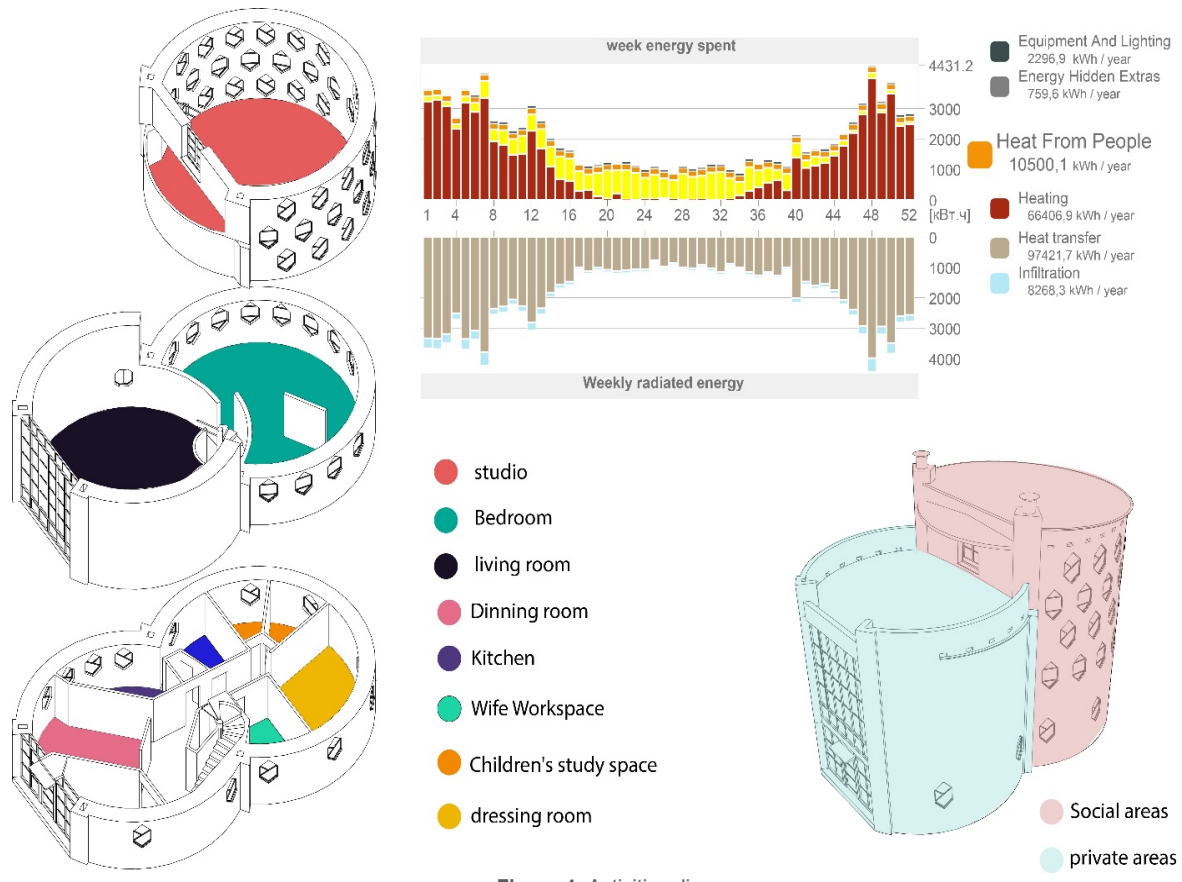

Figure 4: Activities diagram

Since it is located on the west side it receives a low amount of sunlight only in the afternoon. This is an area with higher temperature since an average stove produces a thermal load of $10350 \mathrm{w}$; it is normally occupied three times a day which is corresponding to the feeding hours; it will usually be occupied by one person doing a light work and producing on average a metabolic sensitive load of $69.6 \mathrm{w} / \mathrm{m} 2$ and $92.8 \mathrm{w} / \mathrm{m} 2$ of latent load.

The study spaces for children there are two of them located on the first-floor of the north cylinder with an area of $4.3 \mathrm{~m} 2$, a height of $2.6 \mathrm{~m}$ and a volume of $11.1 \mathrm{~m} 3$. They are located on the northwest side which is an adequate guidance to be protected from overheating and it receives convenient indirect light, suitable for the study activities, receiving sun rays in the afternoon hours when school students work on their home task. It is usually occupied by a person in transferring position who produces on average a sensitive metabolic load of 69.6 $\mathrm{w} / \mathrm{m} 2$ and $92.8 \mathrm{w} / \mathrm{m} 2$ of latent load.

The dressing room it is $11 \mathrm{~m} 2$ with a height of $2.6 \mathrm{~m}$, with a volume of $28.6 \mathrm{~m} 3$ and it is located in the northeast, given its location it receives sunlight in the morning hours when the inhabitants of the house change their clothes to start their daily activities, its second moment of occupation occurs at night when they change their clothes to go to sleep. It is usually occupied by 4 people in idle state with low activity producing on average a sensitive metabolic load of $63.8 \mathrm{w} / \mathrm{m} 2$ and a latent load of $52.2 \mathrm{w} / \mathrm{m} 2$ each for a total of $255 \mathrm{w} / \mathrm{m} 2$ of sensitive load and $208 \mathrm{w} / \mathrm{m} 2$ of latent load.

The wife's office space is located on the first-floor north cylinder, with an area of $5.4 \mathrm{~m} 2$, a height of $2.6 \mathrm{~m}$ and a volume of $14 \mathrm{m3}$, it is located to the east and given its location the window there receives sunlight only in the morning hours throughout the year. It is usually occupied by 1 person in idle state with low activity producing on average a sensitive metabolic load of $63.8 \mathrm{w} / \mathrm{m} 2$ and a latent load of $52.2 \mathrm{w} / \mathrm{m} 2$.

\section{SECOND FLOOR}

The bedroom is located on the second floor in the north cylinder, it is $40 \mathrm{~m} 2$ with a height of $2.6 \mathrm{~m}$ and a volume of $104 \mathrm{~m} 3$, it receives indirect lighting most of the year and it is usually occupied only at night by 4 people in an idle state producing on average a sensitive metabolic load of $53, \mathrm{w} / \mathrm{m} 2$ and latent load of $35 \mathrm{w} / \mathrm{m} 2$ each, for a total of $212 \mathrm{w} / \mathrm{m} 2$ load sensitive and $140 \mathrm{w} / \mathrm{m} 2$ latent load.

Also, the living room is located on the second-floor south cylinder, it is $50 \mathrm{~m} 2$, and a height of $4.8 \mathrm{~m}$ with a volume of $240 \mathrm{m3}$; it is located in the south and occupied only at night receiving direct lighting during most of the year. It is usually occupied by 4 people in idle state generating on average a sensitive metabolic load of $69.6 \mathrm{w} / \mathrm{m} 2$ and a latent load of $63.8 \mathrm{w} / \mathrm{m} 2$ each, for a total of $278 \mathrm{w} / \mathrm{m} 2$ sensible load and a $255 \mathrm{w} / \mathrm{m} 2$ latent load.

\section{THIRD FLOOR:}

The workshop is located on the third floor of north cylinder, it is $50 \mathrm{~m} 2$, with a height of $4.8 \mathrm{~m}$ and a volume of $240 \mathrm{~m} 3$ its north location protects it from overheating and also let it to receive indirect daylight throughout the year. The workshop can be usually occupied from dawn to dusk by one person in a constant activity producing on average a sensible metabolic load of $92.8 \mathrm{w} / \mathrm{m} 2$ and latent load of $185.6 \mathrm{w} / \mathrm{m} 2$, which are the most convenient for this architecture office. 


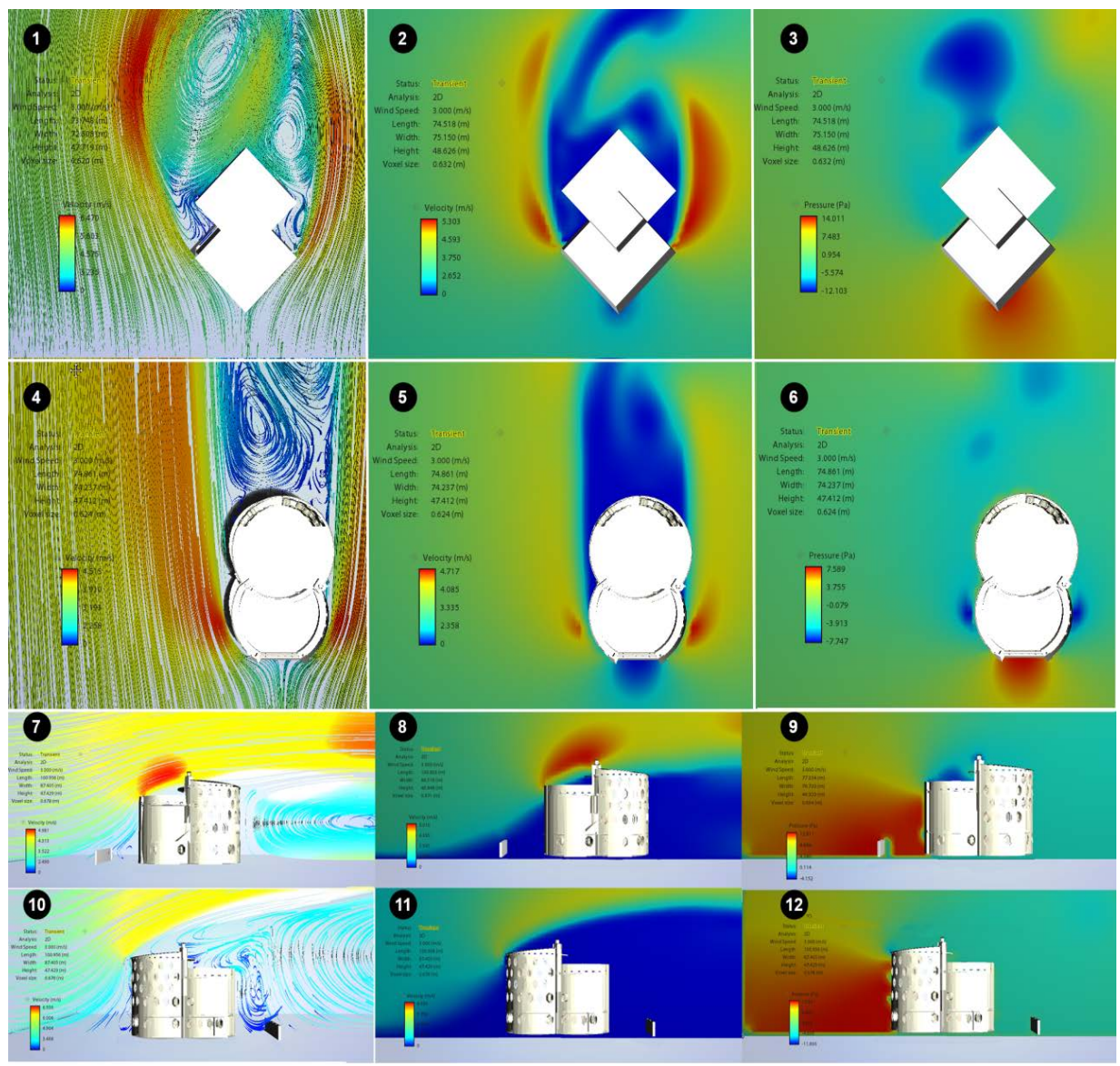

Figure 5: fluid dynamic simulation diagram

\section{4-FORM AND ITS CONNECTION WITH THE OUTSIDE}

The form in architecture has numerous definitions. In this section it is explained how the surfaces and materials limit the architectural space. In order to allow the spaces to fulfill their functions it is also necessary to control the variations in temperature and the inside and the outside air exchanges. The characteristics of the surface that limits the space depend on: The renewal of the air exchanging unpleasant odors, smoke and gases for clean and fresh air, the relation of resistance or docility versus the wind and the gains or heat losses (Sobin \& Olgyay, 1963).

This is why the knowledge of wind-dependent variables such as speed, pressure, direction and turbulence and their relationship with form are decisive for the creation of spaces that provide the dweller with adequate comfort while minimizing the use of mechanical air conditioning systems. The Melnikov House will simulate two relevant factors of its configuration: The geometric shape and the surface enclosure. The relationship between shape and the wind streams as well as the way the surface enclosure connects to the outside will be analyzed below (Wang \& Guo, 2012).

In the following fluid dynamic simulation diagram (Figure 5) the effects on the building caused by the winds are reviewed, having as an initial data a maximum wind speed of $3 \mathrm{~m} / \mathrm{s}$ in the urban areas of Moscow. Because of the absence of wind coming from the western and eastern sides which are blocked by nearby buildings, only the wind input from the two only predominant directions either during the summer from the north, or during the winter from the southwest is being analyzed.

The first three diagrams are a hypothetical comparison between the behavior of the first version of the Melnikov house of $45^{\circ}$ orthogonal form with the same initial conditions of the Melnikov House in its latest version (Maurano, 2013), where the performance in relation to the wind is evident and it is demonstrated that the values of speed is $6.4 \mathrm{~m} / \mathrm{s}$, pressure of 14 pascals and turbulences of $4 \mathrm{~m} / \mathrm{s}$ are greater for this type of geometries. 


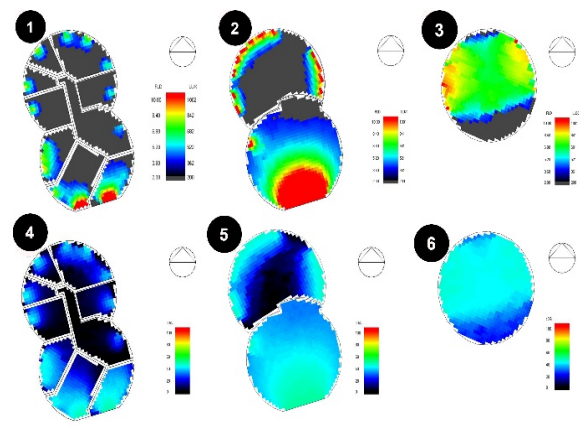

Figure 6: Daylight Factor and the Spatial Daylight Autonomy

The diagrams 4 and 5 for the Melnikov House display the behavior of the winds coming from the south showing an increase of the speed in the eastern and western sides from $3 \mathrm{~m} / \mathrm{s}$ to $4.7 \mathrm{~m} / \mathrm{s}$. Also, in the leeward there is turbulence although with zero speed value; next to it the diagram number 6 displays the pressure the wind is applying on the south façade with a value of 7.5 Pascals, and in addition to this, a negative pressure due to the increase of the wind speed applied on the sides.

Diagrams number 7 and 8 represent two sections showing the behavior of the south wind proving how the low wall in the front yard is a barrier that reduces and diverts the wind. It is also shown the increase in its speed when closer to the top of the terrace. It is also evident that there is low speed turbulence on the north face: The elevation 9 shows that the pressure is exerted by the wind on the east façade with a value of 12 Pascals.

Diagrams 10 and 11 represent two sections showing the behavior of the wind coming from the north. It is observed how the slope of the deck diverts the trajectories upwards and produces air with negative pressure to the leeward and also that there is a turbulence of low speed in the south terrace. The elevation number 12 shows the pressure that is exerted by the wind on the facade with a value of 17 Pascals.

\section{CONTACT BETWEEN THE HOUSE AND THE OUTSIDE}

The heat is transferred between the interior and exterior of a building mainly conducted through the surfaces. This means that the heat is transmitted across the molecules without them moving, thus in cold climates the house must reduce the contact surface to the outside in order to avoid the loss of energy through the materials and their form.

The Melnikov's House design optimizes the surface volume ratio through the use of cylindrical shapes. Among the properties of the cylinder it can be observed its smaller surface of contact and greater volume compared to a cube. An example of this is that in order to fit $1000 \mathrm{~m} 3$ of volume with a cube it is necessary that its measures one $10 \mathrm{~m}$ on each side and its surface will be $600 \mathrm{~m} 2$, while with a cylinder with the same height to contain the same amount of volume it is only required a surface of $554 \mathrm{~m} 2$. Therefore, the cylinder is more compact than the cube and this difference decreases the amount of material used for the construction and the amount of energy exterior. Moreover, the even shape of the building avoids incoming or outgoing parts decreasing the heat losses creating favorable conditions in the winter time.

\section{5-INTERIOR LIGHTING}

The use of sunlight within the space is known as natural lighting and it is an important environmental factor because the correct visibility in a space determines the comfort with which we perform our activities. It is currently expected that natural light not only provides sufficient space but also the balance between heat gains and glare, responding to variations in availability during the day.

In this section we review the behavior of natural light for indoor spaces by simulating the Daylight Factor (DF) and the Spatial Daylight Autonomy (SDA) (Figure 6). The Daylight Factor (DF) is the ratio representing the amount of available indoors illumination against outdoors lighting at the same time under cloudy skies (Kubba, n.d.).

On the other side, Spatial Daylight Autonomy (SDA) describes the amount of space receiving enough daylight. It specifically describes the percentage of floor area receiving at least 300 lux for at least $50 \%$ of the annual occupied hours.

In the first three graphs the simulation of the daylight factor is observed. The evaluation of the light qualities using this factor requires the revision of the following criteria:

1. To evidence, using computer simulations, the area where the levels of illuminance reaches from 300 to 3,000 lux at 9:00 am and 3:00 pm taking a clear equinox day. If $75 \%$ or more of the floor area meets these criteria then a value of 1 is obtained. If $90 \%$ or more of the floor area meets these criteria then a value of 2 is obtained. It can be also observed that two of the main spaces of the house comply fully to this evaluation criteria: The workshop reaches a value of 2 while the living room reaches 1 . Space with high lighting requirements for its activity.

2. The second criteria for evaluating the quality of natural light is to demonstrate, through annual computer simulations, that the SDA autonomy of natural light is achieved. From this simulation it can be observed in graphs 4, 5 and 6 that the workshop and the room having percentages higher than $50 \%$ of their area with 300 lux throughout the year, fulfilling again these spaces with light quality.

\section{6-TREES}

It is important to say that the landscape development of the Melnikov House also influences its interior comfort; the used trees are deciduous (a bird-cherry tree and two birches). Then, during the summer they are leafy and help to cool the air with its leaves protecting the southern facade from the sun, but during the winter they lose their leaves and allow solar rays to go through and warm the interior spaces and the walls of the house. 


\section{CONCLUSIONS}

In this bioclimatic analysis of the Melnikov House it is shown that the origin of the image of the Melnikov house is determined by the climatic and physical context of Moscow, creating an inseparable relationship between the place and the architecture; there the architect considered the efficiency and energy saving; the bioclimatic strategies implemented by Melnikov generated improvements in the thermal behavior of the house.

The simulations allow us to measure the passive strategies used in this house. The characteristics studied and their advantages are the following:

1. Location on the property: The Melnikov house orientation maximizes the light and temperature properties offered by the sun. This house is a solar object that cannot be moved from its original location. Because it is surrounded by buildings, the current location is the one that best avoids being in the shade. Any movement in the south-north or east-west axis will reduce the light received by the house. The location proposed by Melnikov is argued to offer the best solar conditions of this property maximizing the solar incidence and minimizing the shaded areas.

2. Solar collection: It is established that design wise Melnikov has a preference for the collection of solar energy, seeking a passive design through direct strategies such as glazing and indirect ones as the use of high inertial thermal masses by using materials such as brick.

3. Distribution of activities: A first idea of the special distribution criteria of the Melnikov house is found in the relation of social zones located in the south cylinder and private zones located in the north cylinder. This first criteria determines the distribution in relation to the sun. The spaces such as the workshop, the wife's working area, and the study space of the children are located in the north, a place where the lighting is indirect and adequate for the study activities. The social spaces such as the dining room, the access and the living room are located to the south allowing the temperature gains not to bother the development of these activities. In addition to this, the spaces have direct connections between the hours of solar incidence and the occupation time, this criteria locates the spaces that will be used in the morning hours on the east side, and those that will be used during the afternoon on the west side. The spaces to be used all day can be located in the north or south sides.

4. Connection between volume and thermal gains: The high ceiling spaces have activities of high metabolic load (workshop) or high occupancy rate per square meter (living room). Low ceiling spaces have low metabolic loads (room) or small work areas (children's study room and wife's working space). It is clear that the relationship between volume and thermal gain allows the heating requirements to be achieved during most part of the year simply through internal gains and solar radiation.

5. Energy performance: It comes from an optimal spatial distribution in relation to activities, hours of occupation and occupancy rate per square meter.
6. Compact shape: The house decreases the amount of material used for its construction and the amount of energy exchange between the interior and exterior surfaces. In addition to this the shape of the building is even, it does not have protruding elements or cavities which may cause heat losses and also to create unfavorable conditions for the winter.

7. Shape and its relationship with the outside: It is seen that the Melnikov house does not withstand the wind, on the contrary its cylindrical shape oppose a low resistance to the wind and tries to adjust its shape to it. Compared to orthogonal geometries the aerodynamic coefficient of resistance in-plant has a behavior similar to the one of the half sphere.

8. Strategies to mitigate wind in section: In the north side the inclination of the roof favors less resistance to the wind preventing infiltration, and in the south side the low wall of the front yard makes an excellent barrier that protects the façade.

9. Indoor lighting: The workshop and the living room meet the highest criteria of contemporary certifications of natural lighting. It is seen that some spaces do not comply with the current lighting evaluation but this does not mean that they cannot be designed aiming for comfort. In the distribution section it is reviewed the moments of use of each space which allows us to highlight the use of natural light in them.

\section{REFERENCIAS}

DeKay, M., \& Brown, G. Z. (2014). Sun, Wind, and Light: Architectural Design Strategies. John Wiley \& Sons.

Dunichkin, I., Poddaeva, O., \& Golokhvast, K. (2019). Studies and evaluation of bioclimatic comfort of residential areas for improving the quality of environment. Building Simulation, 12(2), 177-182. doi: 10.1007/s12273-018-0495-z

Givoni, B., (1982). Man, Climate and Architecture. London: Applied Science Publishers.

Holyoke, T., \& Heschong, L. (1980). Thermal Delight in Architecture. The Antioch Review, 38(2), 260. doi: $10.2307 / 4638315$

Khan-Magomedov, S., (2007). Konstantin Mel'nikov. Moskva: Arkhitektura-S.

Kuznetsov, P., (2017). The Melnikov House. Icon of Modernism, Family Home, Architecture Museum. Berlin: DOM Publishers.

Maurano, S. (2013). MÉLNIKOV EN PARÍS, 1925. Slovo. doi $10.14324 / 111.0954-6839.006$

Sayigh, A. (2019). Sustainable Vernacular Architecture. Springer

Schneider, B., (2012). Climate model simulation visualization from a visual studies perspective. Wiley Interdisciplinary Reviews: Climate Change, 3(2), pp.185-193.

Sobin, H., \& Olgyay, V. (1963). Design with Climate: Bioclimatic Approach to Architectural Regionalism. Journal of Architectural Education (1947-1974), 18(3), 43. doi: $10.2307 / 1424217$

Wang, X., \& Guo, S. (2012). Parametric Design of Wind Turbine Blades Based on Pro/E. Advanced Materials Research, 580 415-418. doi: 10.4028/www.scientific.net/amr.580.415 